\title{
Trends and seasonality of extreme precipitation characteristics related to mid-latitude cyclones in Europe
}

\author{
A. Karagiannidis, T. Karacostas, P. Maheras, and T. Makrogiannis \\ Dept. of Meteorology and Climatology, School of Geology, Faculty of Science, Aristotle University of Thessaloniki, Greece
}

Received: 24 December 2008 - Revised: 19 March 2009 - Accepted: 27 March 2009 - Published: 30 March 2009

\begin{abstract}
An attempt is made to study the extreme precipitation characteristics, which are related to the mid-latitude cyclonic systems. Daily pluviometric data, from several stations across the continental Europe and the British Islands, are used. The covered time-period is from 1958 to 2000. Only extreme precipitation events related to midlatitude cyclonic systems are studied, since thermal thunderstorm episodes are being excluded. To accomplish that, summer months are excluded and a strict criterion for identifying the exact episodes is set, which also defines the episode itself and the extremity of it. A decreasing trend in the cases of extreme precipitation of the European continent was found. It starts in the mid 60's and continues until the mid 70's. After that and until the end of the examined period, no significant trend was found. Seasonality of extreme precipitation cases and episodes is also studied. October and November are the two months that present the higher frequencies of such cases and episodes. In general, autumn months indicate the higher percentages of extreme precipitation, with winter and spring months to follow.
\end{abstract}

\section{Introduction}

It is believed that climatic changes affect all aspects of weather and climate (Radinović and Ćurić, 2009; Lehner et al., 2006) including the extreme precipitation events. A lot of scientific work has already been done on the subjects related to trends and seasonality of extreme precipitation. As it was expected, the outcomes are not all of them on the same mode. Mudelsee et al. (2003) and New et al. (2001) showed a decreasing trend in the second half of the 20th century, while Moberg and Jones (2005) and Klein Tank and Können (2003) showed an increasing one. Analogous studies performed for

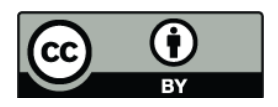

Correspondence to: A. F. Karagiannidis (thankar@geo.auth.gr) several parts of Europe by many researchers (De Luís et al., 2000; Frei and Schär, 2000; Osborn et al., 2000; Xoplaki et al., 2000; Brunetti et al., 2001; Rodrígez Puebla et al., 2001; Brunetti et al., 2002; Maheras et al., 2004; Schmidli and Frei, 2005; Feidas et al., 2007; Nastos and Zerefos, 2007), showing that trends vary widely among the different areas and the examined periods, as well.

On the other hand, inadequate seems to be the studies of trends and seasonality of extreme precipitation events that are produced by mid-latitude cyclonic systems only. In most of the related studies, researchers treat all the kind of precipitation in the same way. In this study, the thermal thunderstorms are excluded, since the summer months are not incorporated in the analysis. Moreover, a strict criterion is used to eliminate thermal thunderstorms that may develop during the rest of the year. With the use of this criterion, the "case" and the "episode" of the extreme precipitation event is also defined and all of them are recorded and studied.

After the identification of the cases and episodes of extreme precipitation events being related to mid-latitude cyclonic systems, the trend of the annual number of cases is examined. The least squares linear regression theory (Wilks, 1995) and the Mann-Kendal non parametric test (Goossens, 1986) are used and applied, and the seasonality of the extreme precipitation events related to mid-latitude cyclonic systems is studied. The percentages of extreme precipitation cases and episodes for each month are calculated in order to identify the months with increased frequency of occurrence of extreme precipitation.

\section{Data used}

Daily pluviometric data from 280 stations across Europe were used in the present study. The covered time period begins in 1958 and ends in 2000. The data were obtained from the European Climate Assessment and Dataset (http:// eca.knmi.nl/), and the Meteorological Services and Institutes of the several European countries, through the STARDEX

Published by Copernicus Publications on behalf of the European Geosciences Union. 


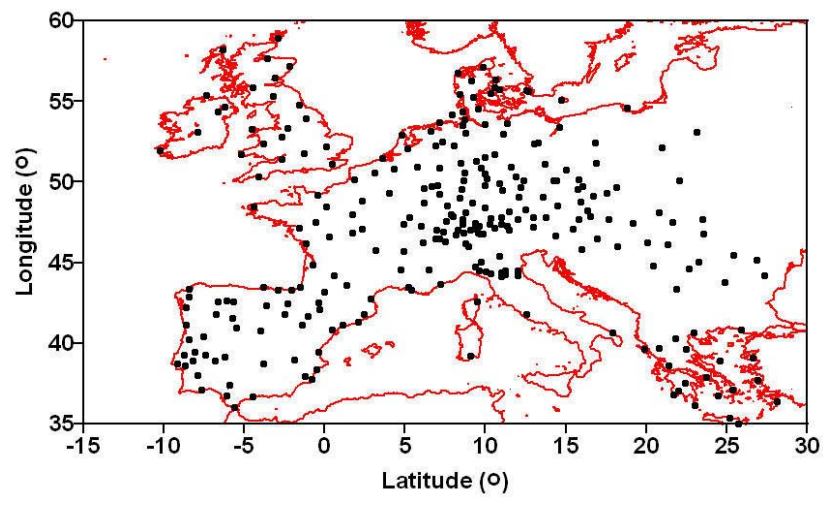

Fig. 1. Spatial distribution of the meteorological stations used.

programme (Statistical and Regional dynamical Downscaling of Extremes for European Regions, http://www.cru.uea. ac.uk/projects/stardex), after its completion.

Figure 1 depicts the spatial distribution of the pluviometric stations used in this work. They cover almost all of the continental Europe, up to $30^{\circ} \mathrm{E}$ longitude, and also the British Islands and Ireland. The density of the stations network is satisfactory for the western Europe, the United Kingdom, Ireland, Czech Republic, Hungary, Romania and Greece. Taking into account the fact that the typical radius of the midlatitude synoptic systems is about $2000 \mathrm{~km}$ (Flocas, 1992), the identification of European extreme precipitation episodes related to mid-latitude cyclonic systems is considered feasible. On the contrary, in the southeast Europe (except Greece and Romania), Poland and central and southern Italy, the network coverage is not quite satisfactory. This fact, however, does not pose a significant problem, since the objective is to study the climatological characteristics of the extreme precipitation episodes and not to analyze in depth every single one of them.

Thermal thunderstorms are developing, almost solely, during the summer months, especially in the southern parts of Europe. Along with the thermal thunderstorms, and the "weak cyclones of thermal origin", which - according to Maheras et al. (2001) - are developing during the warm season at the lower latitudes and are associated with high intensity and significant amount of rainfall. The majority of them are local and limited area systems and they are not associated with mid-latitude cyclonic systems. Therefore, to avoid events related to thermal thunderstorms and "weak cyclones of thermal origin", summer months are not incorporated in this study.

The elimination of the thermal thunderstorms and the "weak cyclones of thermal origin" might incorporate some risk on the exact identification of them, which it is believed to be very small and the affect not significant.

\section{Case and episode of extreme precipitation}

The exclusion of the thermal thunderstorms and the "weak cyclones of thermal origin" from the data set, by eliminating the summer months, could introduced some small random error. Under these circumstances, the homogeneity of the analyzed data is substantial, and this can be achieved by introducing well defined decisive factors produced through the theoretical background knowledge. Hence, it is necessary to develop a criterion, well established and theoretically sound, which will rely upon the definitions of the "case" and the "episode" of the extreme precipitation event. These definitions are based on the spatial and the temporal characteristics of the thermal thunderstorms (Haltiner and Martin, 1957; Holton, 1992) and the definition of "heavy" rainfall event according to the "Glossary of Meteorology" (Huschke, 1959). Based upon the aforementioned, an "extreme precipitation case" is defined as the event of recording more than $60 \mathrm{~mm} /$ day of precipitation at a single station. On the other hand, an "extreme precipitation episode" is defined as the event that fulfils the following two rules:

1. The recording precipitation exceeds the $60 \mathrm{~mm}$, on the same day, at least at two neighbouring stations. Two stations are characterized as neighbouring when their distance is less than $550 \mathrm{~km}\left(d_{\max }<550 \mathrm{~km}\right)$.

2. On the previous or the following day of the event, at least one station to record precipitation more than $60 \mathrm{~mm} /$ day. This station could be, either one of the stations satisfying rule (a), or another one, being located within the limits of the defined neighbouring area.

It should be mentioned, that if one, or both, of the aforementioned rules of the criterion is satisfied for two or more consecutive days, then these days are considered to be part of the same episode. Therefore, extreme precipitation episodes are related solely to mid-latitude cyclonic systems and they are considered to be free of recordings related to thermal thunderstorms.

\section{Trends of extreme precipitation}

Time-series analyses of the annual number of the extreme precipitation cases are performed for each one of the used stations, in order to investigate any possible trend. Figure 2a depicts the change of the annual number of extreme precipitation cases during the whole studied period (1958-2000). The least squares regression line is also drown. An overall negative slope $(-0.38)$ of the regression line is demonstrated, which corresponds to a decrease of approximately four (4) extreme precipitation cases per year for every 10 years period. This value is considered significant, taking into account the overall average number of extreme precipitation cases per year, which is 75.2 . 

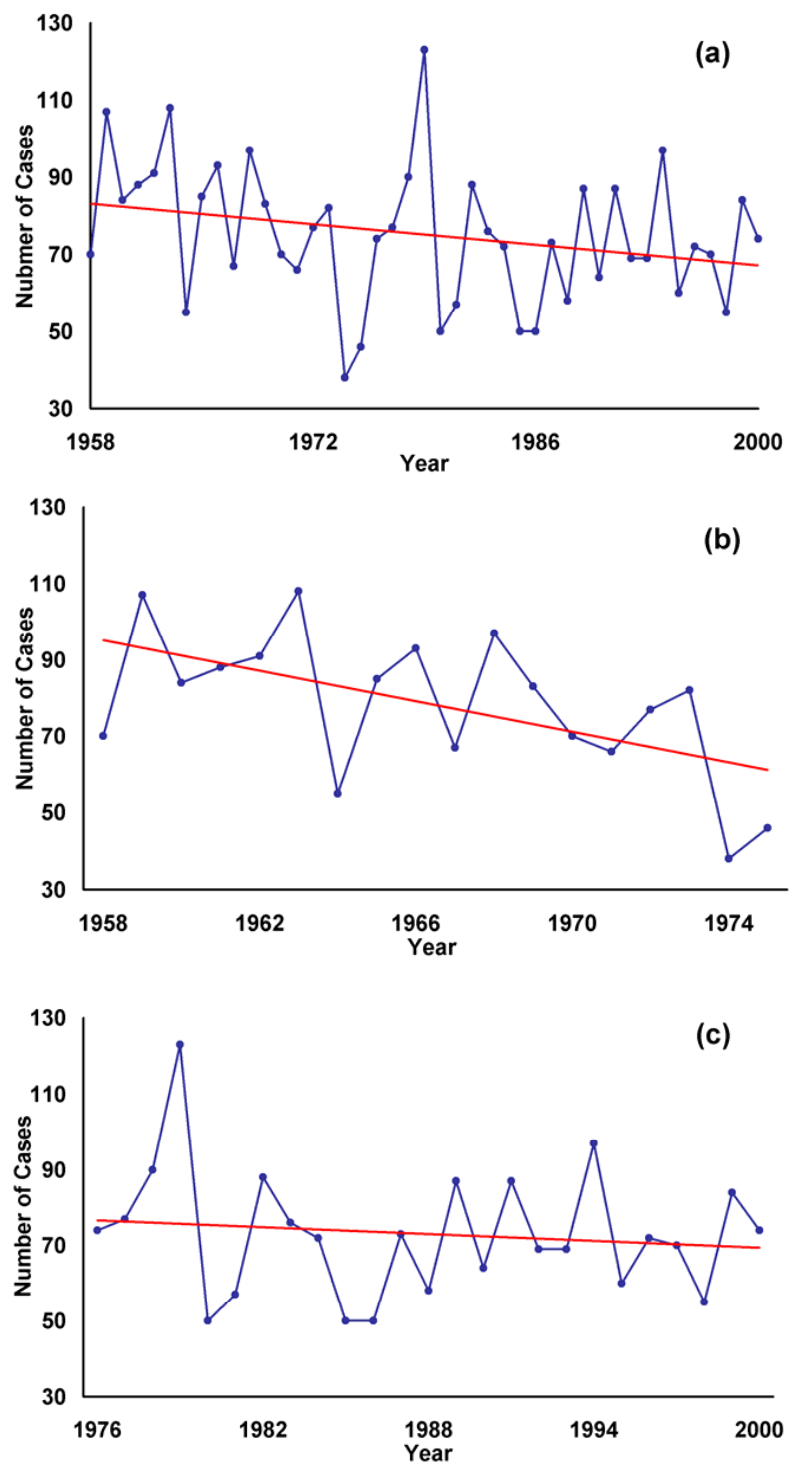

Fig. 2. Number of the extreme precipitation cases as a function of time (blue line) and least squares regression line (red line) for three time periods: (a) 1958-2000, (b) 1958-1975 and (c) 1976-2000.

The time-series of the annual number of the extreme precipitation cases during the two sub-divided periods (19581975 and 1976-2000), are illustrated in Fig. 2b and c. The least squares regression lines are also drawn. A decreasing trend, much greater than the one found for the whole period, is observed for the sub-period 1958-1975 (Fig. 2b). The regression line slope for this period is -1.99 , which corresponds to a decrease of approximately 20 extreme precipitation cases for every 10 years. This decrease is quite remarkable. In this case, the overall average number of extreme precipitation cases per year is 80.1. For the second sub-period, as it is depicted in Fig. 2c, a smaller decreasing trend is found. The slope of the regression line is -0.30 , a

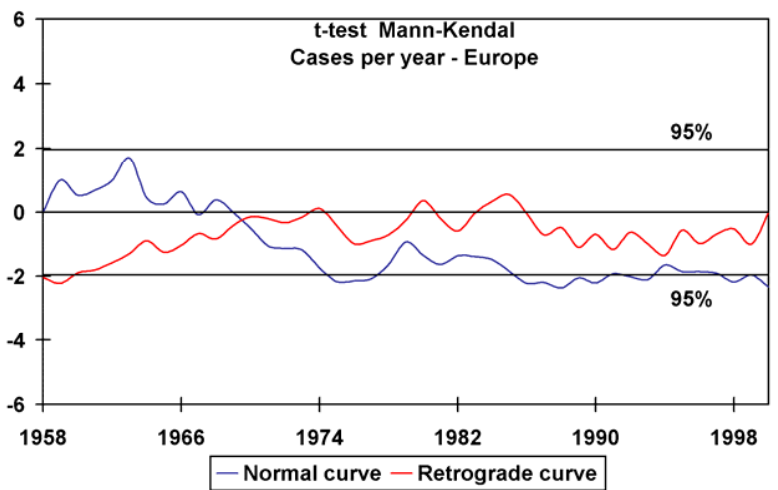

Fig. 3. Normal and retrograde curve of the Mann-Kendall test of the total number of the extreme precipitation cases per year for all the European stations.

little smaller - in absolute value - than the one found for the whole period.

Summing up, a remarkable negative trend is noticed for the number of extreme precipitation cases per year, from the beginning of the examined period until the mid 70's. Afterwards, the trend becomes significantly smaller, but still existing, from the mid 70's to the end of the century.

These results are in good agreement with the results founded from the application of the non-parametric MannKendall test (Goossens, 1986) on the same time-series data. Figure 3 illustrates the normal and the retrograding curve of the test, for the number of extreme precipitation cases per year for the whole period 1958-2000. The 95\% significance level is also depicted with the two continuous lines, parallel to the time axis. A negative trend is recorded after 1963, which becomes statistically significant during the years 1975-1977. No significant trend is found afterwards until the end of the examined period.

From the combination of the two aforementioned methods, it can be said that the total number of extreme precipitation cases per year present a continuous, statistically significant decreasing trend until the mid 70's. No significant, positive or negative trend is evident afterwards. It should be stated that this conclusion is valid only for the continental Europe, the British Islands and Ireland.

Previous studies on the extreme precipitation trends over the same area are rather rare, making the comparison of the findings a difficult task. Moreover, the exclusion of the summer months could be a justified parameter of any discrepancy that might exist between these conclusions and those of other studies, which happen not do exclude summer months. On the other hand, there is a number of papers on trends of monthly, seasonal or annual precipitation events for a variety of regions and time-periods. Their results should be compared to these of the present study, as they are considered to be relevant in subject and scope. 


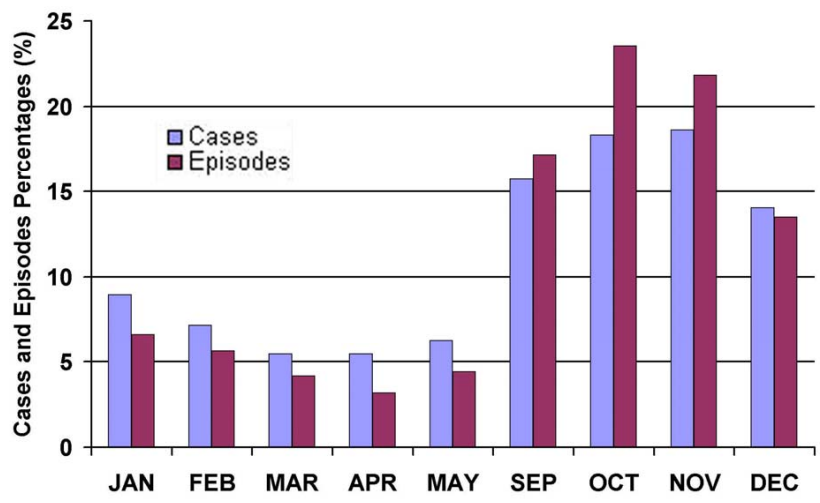

Fig. 4. Percentage of the total number of the extreme precipitation cases and the extreme precipitation episodes per month.

Mudelsee et al. (2003) showed a possible decreasing trend in the occurrence of extreme floods in central Europe. Moreover, a decrease of the mean monthly amount of precipitation was observed during the winter, for some European regions. New et al. (2001), on their attempt to study the global precipitation, concluded that annual precipitation values presented a maximum in the 1950's, followed up by a decreasing trend. This trend coincides with the one found for the extreme precipitation case in the present study. However, New et al. (2001) do not mention any positive or negative trends of the extreme precipitation in Europe, with the only exception, the increase of the summer rain in Poland. Moberg and Jones (2005), studying a series of indices for central and western Europe, found increasing trends, for the average precipitation intensity and for the moderately strong events. Analogous were the conclusions of Klein Tank and Können (2003), whose findings resulted to an increasing trend of the total precipitation and the precipitation of "moderate" and "very wet" days in Europe for the period 19461999. It should be noted, that the increasing trends found by Klein Tank and Können were observed mainly at stations of high latitudes.

\section{Seasonality of the extreme precipitation}

In order to study the seasonal distribution of extreme precipitation in Europe, the total number of cases and episodes of extreme precipitation for each month was calculated. Their percentage was also calculated. Table 1 shows the total number and percentage of the cases and episodes of extreme precipitation for each month. It should be noted that if an episode extends in two months, it is counted as half episode for each one of these two months.

From Table 1 and Fig. 4 becomes evident that November depicts the highest percentage of the cases of the extreme precipitation events, reaching the value of $18.63 \%$. October follows up with $18.32 \%$, while significant percentages
Table 1. Total number and percentage of the extreme precipitation cases and the extreme precipitation episodes for the whole European continent.

\begin{tabular}{lllll}
\hline Months & $\begin{array}{l}\text { Total Number } \\
\text { of cases }\end{array}$ & $\begin{array}{l}\text { Percentage } \\
\text { of cases }(\%)\end{array}$ & $\begin{array}{l}\text { Total number } \\
\text { of episodes }\end{array}$ & $\begin{array}{l}\text { Percentage } \\
\text { of episodes (\%) }\end{array}$ \\
\hline Jan & 289 & 8.94 & 13.5 & 6.62 \\
Feb & 232 & 7.18 & 11.5 & 5.64 \\
Mar & 176 & 5.45 & 8.5 & 4.17 \\
Apr & 176 & 5.45 & 6.5 & 3.19 \\
May & 203 & 6.28 & 9.0 & 4.41 \\
Sep & 508 & 15.72 & 35.0 & 17.16 \\
Oct & 592 & 18.32 & 48.0 & 23.53 \\
Nov & 602 & 18.63 & 44.5 & 21.81 \\
Dec & 454 & 14.05 & 27.5 & 13.48 \\
\hline
\end{tabular}

are found in September and December with $15.72 \%$ and $14.05 \%$, respectively. With respect to the extreme precipitation episode percentages, October is the dominant month with $23.53 \%$, followed up by November now, with $21.81 \%$. September and December, as it was expected, present significant percentages with $17.16 \%$ and $14.05 \%$, respectively. The percentages of the rest of the months are below $10 \%$.

Two interesting features should be pointed out. Firstly, the autumn months accumulate most of the cases and episodes of extreme precipitation. Winter months follow, whilst a really small percentage remains for the three spring months. Secondly, the percentages of extreme precipitation episodes for the months of April, May and January are lower compared to those of the extreme precipitation cases. On the other hand, the percentages of the extreme precipitation episodes for the months September, October and November are greater than the percentages of the cases. This fact could be attributed to the higher frequency of occurrence of thermal thunderstorms during the spring months, than during autumn or winter months. Although the ensemble of the extreme precipitation episodes is considered to be free of thermal thunderstorms, the one of the extreme precipitation cases usually is not.

\section{Discussion and conclusions}

Linear regression methodology and the non-parametric Mann-Kendall test were used to identify possible trends in European extreme precipitation events that are related to mid-latitude cyclonic systems. Thermal thunderstorms were excluded from the study through the elimination of summer months recordings and the implementation of a sound criterion of selection of events. Continental Europe as a whole, Great Britain and Ireland present a statistically significant negative trend for the total number of extreme precipitation cases per year. This trend starts in the early 60's and reaches the mid 70's. Afterwards, the trend becomes significantly smaller, but still exists, from the mid 70's to the end of the century. 
The seasonal distribution of the extreme precipitation cases and episodes was also examined. October and November are the dominant months regarding the frequency of occurrence of the extreme precipitation events. In a more general approach, most of the extreme precipitation cases were found in autumn months, with the winter months to follow up. The smallest percentages were encountered on the three spring months. The distribution for the extreme precipitation episodes is very similar.

Edited by: S. C. Michaelides

Reviewed by: two anonymous referees

\section{References}

Brunetti, M., Maugeri, M., and Nanni, T.: Changes in total precipitation, rainy days and extreme events in northeastern Italy, Int. J. Climatol., 21, 861-871, 2001.

Brunetti, M., Maugeri, M., Nanni, T., and Navarra, A.: Droughts and extreme events in regional daily Italian precipitation series, Int. J. Climatol., 22, 543-558, 2002.

De Luís, M., Raventós, J., González Hidalgo, J. C., Sánchez, J. R. and Cortina, J.: Spatial analysis of rainfall trends in the region of Valencia (east Spain), Int. J. Climatol., 20, 1451-1469, 2000.

Feidas, H., Noulopoulou, C., Makrogiannis, T., and Bora-Senta, E.: Trend analysis of precipitation time series in Greece and their relationship with circulation using surface and satellite data: 19552001, Theor. Appl. Climatol., 87, 155-177, 2007.

Flokas, A. A.: Lessons in meteorology and climatology (in Greek), Zitis publications, Thessaloniki, 1992.

Frei, C. and Schär, C.: Detection Probability of Trends in Rare Events: Theory and Application to Heavy Precipitation in the Alpine Region, J. Climate, 14, 1568-1584, 2000.

Goossens, C. and Berger, A.: Annual and seasonal climatic variations over the Northern Hemisphere and Europe during the last century, Ann. Geophys., 4 B., 385-400, 1986.

Haltiner, G., Martin, F.: Dynamical and Physical Meteorology. McGraw-Hill Book Company, New York, 1957.

Holton, J. R.: An Introduction to Dynamic Meteorology, Third Edition. Academic Press, San Diego California, 1992.

Huschke, R. E.: Glossary of Meteorology, Amer. Meteor. Soc., Boston Massachusetts, 1959.

Klein Tank, A. M. G. and Können, G. P.: Trends in Indices of Daily Temperature and Precipitation Extremes in Europe, 1946-99, J. Climate, 16, 3665-3680, 2003.
Lehner, B., Döll, P., Alcamo, J., Henrichs T., and Kaspar, F.: Estimating the Impact of Global Change on Flood and Drought Risks in Europe: A Continental, Integrated Analysis, Clim. Change, 75, 273-299, 2006.

Maheras, P., Flocas, H. A., Patricas, I., and Anagnostopoulou, C.: A 40 year objective climatology of surface cyclones in the Mediterranean region: spatial and temporal distribution, Int. J. Climatol., 21, 109-130, 2001.

Maheras, P., Tolika, K., Anagnostopoulou, C., Vafiadis, M., Patrikas, I., and Flocas, H.: On the relationships between circulation types and changes in rainfall variability in Greece, Int. J. Climatol., 24, 1695-1712, 2004.

Moberg, A. and Jones, P. D.: Trends In Indices For Extremes In Daily Temperature and Precipitation In Central And Western Europe, 1901-99, Int. J. Climatol., 25, 1149-1171, 2005.

Mudelsee, M., Börngen, M., Tetzlaff, G., and Grünewald, U.: No upward trends in the occurrence of extreme floods in central Europe, Nature, 425, 166-169, 2003.

Nastos, P. T. and Zerefos, C. S.: On extreme daily precipitation totals at Athens, Greece, Adv. Geosci., 10, 59-66, 2007, http://www.adv-geosci.net/10/59/2007/.

New, M., Todd, M., Hulme, M., and Jones, P.: Precipitation measurements and trends in the Twentieth Century. Review Article, Int. J. Climatol., 21, 1889-1922, 2001.

Osborn, T. J., Hulme, M., Jones, P. D., and Basnett, T. A.: Observed trends in the daily intensity of United Kingdom precipitation, Int. J. Climatol., 20, 347-364. 2000.

Rodríguez-Puebla, C., Encinas, A. H., and Sáenz, J.: Winter precipitation over the Iberian peninsula and its relationship to circulation indices, Hydrol. Earth Syst. Sci., 5, 233-244, 2001, http://www.hydrol-earth-syst-sci.net/5/233/2001/.

Radinović, D. and Ćurić, M: Deficit and surplus of precipitation as a continuous function of time, Theor. Appl. Climatol., doi:10.1007/s00704-009-0104-2, 2009.

Schmidli, J. and Frei, C.: Trends of heavy precipitation and wet and dry spells in Switzerland durinh the 20th century, Int. J. Climatol., 25, 753-771, 2005.

Wilks, D. S.: Statistical methods in the atmospheric sciences. Academic Press, 1995.

Xoplaki, E., Luterbacher, J., Burkard, R., Patrikas, I., and Maheras, P.: Connection between the large-scale $500 \mathrm{hPa}$ geopotential height fields and precipitation over Greece during wintertime, Clim. Res., 14, 129-146, 2000. 